\title{
ASPECTOS DE HIPOSEGMENTAÇÃO E HIPERSEGMENTAÇÃO NA ESCRITA DE CONTOS PRODUZIDOS NA ESCOLA
}

\section{HYPOSEGMENTATION AND HYPERSEGMENTATION ASPECTS IN WRITING OF SCHOOL-PRODUCED SHORT STORIES}

\author{
Ana Clécia Maria da Silva Nemésio dos Santos ${ }^{58}$ \\ Maria do Rosário da Silva Albuquerque Barbosa ${ }^{59}$
}

\begin{abstract}
RESUMO: Este estudo traz uma reflexão do uso da segmentação não-convencional em textos escritos por alunos do $7^{\circ}$ do Ensino Fundamental, matriculados em escola pública, e analisa contos escritos em ambientes didáticos distintos, durante um projeto de leitura e de escrita desenvolvido no Ensino Fundamental. A relevância desse estudo reside numa proposta didática para diminuir equívocos de escrita, a partir da leitura e escrita de contos. Além disso, este trabalho se inspira numa metodologia do ensino australiano. Para tanto, identificamos e categorizamos fenômenos linguísticos considerados não-convenções da língua escrita, de origem fonológica e grafo-fonológica, não adequados à norma padrão escrita, constatando maior incidência de hipo e hipersegmentação de palavras em vinte contos escritos. Para fundamentar esta pesquisa, utilizamos os estudos de Rothery (1994; 1996), Martin e Rose (2008) e Rose e Martin (2012) sobre a Pedagogia de Gêneros, desenvolvidos pelos estudiosos da Escola de Sidney, além dos estudos de Bortoni-Ricardo e Cagliari (2009) sobre escrita, Cunha (2004), Tenani $(2011,2014)$ sobre segmentações não-convencionais. Os resultados demonstram um processo de letramento escolarizado dos participantes, apontando flutuação na linguagem, pois ora o estudante escreve fugindo às normas ortográficas, ora escreve conforme a convenção da língua.
\end{abstract}

PALAVRAS-CHAVE: Escrita. Hipossegmentação. Hipersegmentação

ABSTRACT: This study reflects on the use of unconventional segmentation in texts written by students from the 7 th grade, enrolled in public schools and analyzes stories written in different didactic environments, during a reading and writing project developed in Elementary School. The relevance of this study lies in a didactic proposal to reduce writing misconceptions, from reading and writing short stories. In addition, this work is inspired by an Australian teaching methodology. To that end, we identified and categorized linguistic phenomena considered non-conventions of the written language, of phonological origin and gram-phonological, not adequate to the standard written standard, noting a higher incidence of hypo and hypersegmentation of words in twenty written short stories. In order to base this research, we use the studies of Rothery (1994; 1996), Martin and Rose (2008) and Rose and Martin (2012) on Pedagogy of Genres, developed by the scholars of the Sydney School, besides studies by Bortoni-Ricardo and Cagliari (2009) on writing, Cunha (2004), Tenani (2011, 2014) on non-conventional segmentations. The results demonstrate a process of schooling of the participants, indicating a fluctuation in the language, because now the student writes to avoid orthographic norms, or writes according to the convention of the language.

KEYWORDS: Writing. Hypothilation. Hypersegmentation

\section{Introdução}

O ensino da escrita no Ensino Fundamental, ainda, revela que o uso de escolhas linguísticas não-convencionais encontra-se presente em textos de alunos matriculados nos anos finais do Ensino Fundamental. Esse fato vem demonstrando que, nesta fase escolar, ao trazer, nas produções escritas, as ocorrências de segmentações não-convencionais o aluno parece cometer erro ortográfico resultante das supostas interferências do oral no escrito. E

\footnotetext{
${ }^{58}$ Docente da SEDUC - Secretaria de Educação do Estado de Pernambuco. Aluna do Mestrado Profissional em Letras (PROFLETRAS). E-mail: anaclecia2009@hotmail.com.

59 Docente do Curso de Letras - Licenciatura em Língua Portuguesa e Língua Inglesa, do Programa de PósGraduação em Letras (UPE). E-mail: mariadorosariobarbosa@yahoo.com.br.
} 
chama nossa atenção, uma vez que Tenani (2011), corroborando com as ideias de Chacon (2004, 2005) e Capristano (2007), salienta que a complexidade de ocorrências da não segmentação na escrita se dá em razão de as ocorrências apresentarem tanto características da oralidade, quanto marcas de um processo de letramento ainda em construção, evidenciando, assim, a multifacetada relação do sujeito com as modalidades língua falada e língua escrita.

Dessa forma, Tenani (2011) ainda explica que a segmentação não-convencional de palavras diz respeito à presença ou à ausência "indevidas", em relação às convenções ortográficas, do espaço em branco que define os limites da palavra escrita. De acordo com a autora, os trabalhos de Abaurre (1998), Silva (1991), Chacon (2004, 2005, 2006), Cunha (2004), Capristano (2007), Paula (2007), Cunha e Miranda (2007) classificam as segmentações em dois tipos: (i) hipossegmentação (as palavras são escritas juntas, como em "siescondeu" e "derrepente") e a hipersegmentação (as palavras são escritas separadas como em "com tinuou" e "com migo"). Articulado aos estudos sobre a relevância da segmentação não-convencional na perspectiva fonológica, este estudo destaca uma análise de ocorrências de estruturas segmentadas de forma não convencional encontradas nas produções de textos escritos de alunos do $7^{\circ}$ ano do Ensino Fundamental. Desse modo, o trabalho teve como objetivo verificar de que forma ocorrem a hipossegmentação e a hipersegmentação em textos produzidos durante um projeto de leitura e escrita desenvolvido na escola.

Os textos selecionados para este estudo foram chamados de produção inicial (PI) e produção final $(\mathrm{PF})$. Ambos produzidos em momentos distintos do projeto: o primeiro foi produzido, após reflexão da temática do conto; e o segundo, após contato com diferentes contos- tanto em relação com a leitura e a escrita.

\section{Sobre as segmentações não-convencionais}

Discutimos aqui os fenômenos da hipossegmentação e os da hipersegmentação. $O$ primeiro, de acordo com Cunha (2004), caracteriza-se pela junção de palavras que deveriam ser grafadas separadamente na escrita, no entanto o aluno as escreve juntas.

O fenômeno de hipossegmentação se constitui de estruturas compostas por duas ou mais palavras, entretanto, conforme as convenções ortográficas deveriam ser grafadas separadas. Nessa perspectiva, Cunha (2004) apud Moreira (1991), postula que a hipossegmentação consiste na "ausência do espaço entre fronteiras vocabulares". Para ela, isso ocorre porque um dos importantes critérios de segmentação usado pela criança é a exigência de uma quantidade mínima de caracteres para que uma palavra venha a ser dividida. A autora defende serem frequentes os casos em que ocorrem a juntura de categorias gramaticais como os artigos, conjunções, preposições e os pronomes átonos às palavras mais próximas. Já para Cagliari (2002), quando a criança inicia o seu processo de aquisição da língua escrita, tem a tendência de juntar todas as palavras e, ao realizar essa juntura, ela estaria usando a fala como referência, já que esta não é segmentada.

Para Moreira (1991), a hipersegmentação trata-se da "alocação no interior da palavra. Segundo a autora, esse fenômeno diz respeito a uma estratégia que a criança usa frequentemente, em que segmenta sílabas de palavras que diz respeito a categorias lexicais e gramaticais. Exemplificando, têm-se: "sol tar" (soltar) - categoria lexical; "com duzido" (conduzido) - categoria gramatical.

Já para Cagliari (2002), a hipersegmentação dos vocábulos, no processo de aquisição da escrita infantil, pode ser uma decorrência da acentuação tônica das palavras, como em "a gora" (agora). Dessa forma, Tenani (2011), ao analisar as ocorrências de hipersegmentação, toma como critério de interpretação o fato de que o escrevente considerou a cadeia fônica como duas unidades prosódicas. Esta autora cita os trabalhos de Abaurre (1988,1989,1991 e 
2011), Abaurre e Cagliari (1995), Abaurre e Silva (1993) para falar que os estudos desses pesquisadores têm mostrado que a presença não convencional de espaços em branco e fatos de natureza fonético-fonológica estão diretamente ligados. Desse modo, para esses autores a motivação das segmentações não-convencionais em determinadas grafias está relacionada à possibilidade de organização prosódica dos enunciados falados.

\section{Sobre a hierarquia prosódica com os elementos linguísticos não-convencionais}

Conforme Cunha (2004), os dados prosódicos são bastante relevantes no processo de aquisição da linguagem, uma vez que são a ponte inicial entre o som e o significado e essa relação leva a criança à aquisição da linguagem. Para a autora, a cadeia da fala é um ato contínuo "e compreender uma língua pressupõe saber dividir mentalmente essa continuidade em componentes psicologicamente significativos. O estudo dessa cadeia da fala é feito pela fonologia prosódica e seus componentes significativos, os constituintes prosódicos" (CUNHA, 2004, p. 39).

Baseando-se na afirmação de Cunha (2004) e de Tenani (2011), ao citar outros pesquisadores, chega-se à conclusão de que, para compreender as ocorrências de hipersegmentação e hipossegmentação, faz-se necessário entender sobre os constituintes prosódicos. Esses constituintes prosódicos, de acordo com Nespor e Vogel (1986 apud Cunha 2004), são fragmentos mentais hierarquicamente distribuídos, aos quais são aplicadas regras fonológicas específicas. Esses constituintes oferecem diversos tipos de informação fonológica ou não-fonológica ao definir o seu âmbito.

Segundo Bisol (1996), todo o constituinte prosódico presume um cabeça, ou seja, a organização desses constituintes dá-se de forma hierarquizada. Para esta autora, o constituinte prosódico "é uma unidade linguística complexa, cujos membros desenvolvem entre si uma relação binária de dominante/dominado, precisamente uma relação de forte/fraco ou vice-versa" (BISOL,2005, p. 255).

Já para Nespor e Vogel (1986 apud Cunha, 2004) existem sete constituintes prosódicos que obedecem a uma hierarquia, a saber: sílaba $(\sigma)$; pé $(\Sigma)$; palavra fonológica $(\omega)$; grupo clítico $(C)$; frase fonológica $(\varphi)$; frase entonacional (I) e enunciado (U). Logo, é mediante a identificação de sílabas fortes e fracas contidas na segmentação das palavras que se verificam o tipo de acento de determinada língua e, consequentemente, o tipo de pé desta língua. Este elemento estrutura-se mediante uma sequência de uma sílaba relativamente forte e as demais relativamente fracas.

A palavra fonológica, terceiro constituinte prosódico, atua dominando o pé métrico e todos os pés de uma sequência. O que vem a caracterizar a palavra fonológica é o fato de ela possuir um acento primário, isto é, uma sílaba tônica. Assim, o elemento fundamental da palavra fonológica é o pé métrico, pois é ele que determina o acento. O quarto constituinte da escala prosódica é o grupo clítico. Na linguística, o clítico é considerado como uma palavra funcional, isto é, aquela que não possui um acento próprio e, por este motivo, não possui independência fonológica e nem sintática. Esse constituinte pertence às classes gramaticais dos artigos, preposições, conjunções e pronomes pessoais átonos.

A frase fonológica é o quinto constituinte da escala prosódica. É aquela que engloba as unidades mais baixas e domina o grupo clítico. Ela tanto pode ser representada por uma locução, como "a arvore", ou ainda por uma palavra fonológica, como "árvore".

\section{Sobre o texto escrito no Ensino Fundamental}

Para realização deste estudo, selecionamos textos produzidos em sala de aula durante a aplicação de uma proposta didática, inspirado num Ciclo de Ensino e Aprendizagem, desenvolvido na Austrália. Trata-se de uma metodologia proposta pelo Programa de letramento australiano Reading to Learn, (Ler para Aprender), proposto por Martin e Rose (2012) em sua fase mais recente, que se baseia em um Ciclo de Ensino e Aprendizagem por meio de gêneros textuais. 
O projeto didático foi intitulado de "Leitura de contos a favor da escrita de textos" compreende a realização de atividades envolvendo leitura, escrita e reescrita de textos e experienciado no $7^{\circ}$ ano do Ensino Fundamental e composto por três níveis e estratégias didáticas, conforme mostra o quadro a seguir:

QUADRO 01: Distribuição dos níveis e estratégias didáticas do projeto

\begin{tabular}{|c|c|c|}
\hline & ESTRATÉGIAS DIDÁTICAS & CH \\
\hline Proposta & Instrução Didática & $1 \mathrm{~h}$ \\
\hline Negociação do Campo & Conhecimento Prévio sobre ao assunto & $5 \mathbf{5 h}$ \\
\hline NÍVEIS & ETAPAS & CH \\
\hline \multirow{3}{*}{ I } & Preparação para a leitura (Desconstrução) & $6 \mathrm{~h}$ \\
\hline & Construção Conjunta & $4 \mathrm{~h}$ \\
\hline & Escrita Autônoma (PRODUÇãO ESCRITA INICIAL) & $2 \mathrm{~h}$ \\
\hline NÍVEIS & ETAPAS & $\mathbf{C H}$ \\
\hline \multirow[t]{2}{*}{ II } & Construção de Períodos & $4 \mathrm{~h}$ \\
\hline & Ortografia & $4 \mathrm{~h}$ \\
\hline Níveis & Etapas & CH \\
\hline \multirow[t]{3}{*}{ III } & Leitura Detalhada & $16 \mathrm{~h}$ \\
\hline & Escrita Autônoma (PRODUÇÃo ESCRITA FINAL) & $4 \mathrm{~h}$ \\
\hline & Reescrita & $8 \mathrm{~h}$ \\
\hline \multicolumn{2}{|c|}{ CARGA HORÁRIA TOTAL } & $50 \mathrm{~h}$ \\
\hline
\end{tabular}

FONTE: Organizado pelas pesquisadoras

Durante o projeto indicado no quadro 1, foram selecionados oitenta textos, considerando quarenta de produção inicial e quarenta de produção final de cada aluno. Desses, apenas vinte textos, totalizando $25 \%$, foram analisados. Esse projeto foi inspirado num programa de letramento que integra atividades de leitura e escrita ao ensino dos conteúdos curriculares em todos os níveis de escolaridade em que se pode atuar e um aspecto central para o desenvolvimento desse programa é o reconhecimento de que ler é importante para a aprendizagem escolar e social.

\section{Sobre o uso da segmentação não-convencional}

Os textos em que foram extraídas as ocorrências das segmentações nãoconvencionais são pertencentes aos alunos de uma turma do sétimo ano do Ensino Fundamental de uma escola pública localizada na região metropolitana do Recife. Assim, para o desenvolvimento deste estudo foram selecionados vinte textos de dez participantes produzidos durante uma proposta de leitura e produção de textos. Conforme o quadro 2, sendo (P), referência aos participantes.

Quadro 2: Quantidade de produção escrita

\begin{tabular}{|l|c|c|c|c|c|c|c|c|c|c|l|}
\hline Produções & P. 1 & P. 2 & P.3 & P.4 & P.5 & P.6 & P.7 & P.8 & P.9 & P.10 & Total \\
\hline $1^{\text {a }}$ Produção & 1 & 1 & 1 & 1 & 1 & 1 & 1 & 1 & 1 & 1 & 10 \\
\hline $2^{\text {a }}$ Produção & 1 & 1 & 1 & 1 & 1 & 1 & 1 & 1 & 1 & 1 & 10 \\
\hline
\end{tabular}

Fonte: Produzido pelas pesquisadoras

Vale salientar que, durante o intervalo da primeira e segunda produção escrita, realizaram-se leituras de narrativas e atividades que tinham por objetivo levar o aluno a refletir sobre os fenômenos de hipossegmentação e hipersementação. Inicialmente, 
consideramos o uso ou não de espaço em branco entre as fronteiras das palavras, bem como recursos linguísticos que, conforme Cunha (2004), abrangem duas variáveis: o tipo de palavra - fonológica ou gramatical - que serão identificados na composição das segmentações não-convencionais produzidas pelos participantes na primeira e segunda produção, assim como o tipo de constituinte prosódico mobilizado nessas estruturas segmentadas de forma não convencional: sílaba (que será representada pelo símbolo grego $\sigma$ ), pé ( representado por $\sum$ ), palavra fonológica (sendo representada pelo símbolo $\omega$ ), grupo clítico ( representado por $\mathrm{C}$ ) e a frase fonológica ( representada por $\Phi$ ).

No que se refere à identificação do variável tipo de palavra, adotamos a proposta de Cunha (2014), que é composta por quatro combinações: a) palavra gramatical + palavra fonológica; b) palavra fonológica + palavra gramatical; c) palavra gramatical + palavra gramatical; d) palavra fonológica + palavra fonológica. E, em relação a variável tipo de constituinte prosódico, focalizamos a identificação das estruturas métricas presentes nas duas modalidades de segmentação pesquisada. Assim, identificamos os tipos de pés métricos que são mais característicos nas segmentações não-convencionais.

No gráfico 1, a seguir, apresentamos o percentual de estruturas hipersegmentadas e hipossegmentadas detectadas nas primeiras e segundas produções.

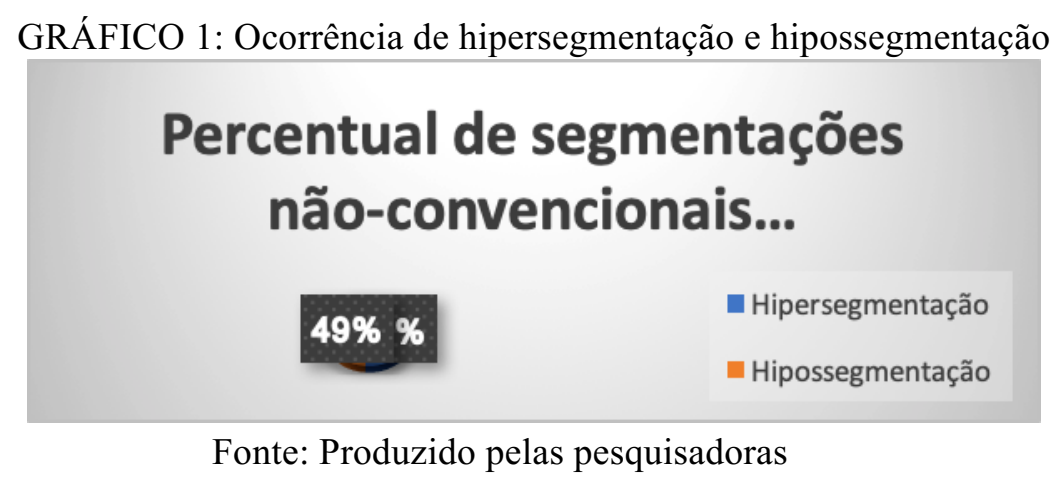

As ocorrências de hipersegmentação foram no total de 87 casos, já os casos de hipossegmentação chegaram em um total de 83 ocorrências. Desta forma, verifica-se uma relação bastante equilibrada entre o número de ocorrências de hipersegmentação (51\%) e o de hipossegmentação (49\%). Baseando-se em pesquisas realizadas por Tenani (2010), esses dados podem ser interpretados como indícios do processo de letramento/ escolarização, pois apesar de esses participantes estarem nos anos finais do Ensino Fundamental, suas escritas assemelham-se àquelas produzidas por estudantes dos anos iniciais desta Modalidade de Ensino.

No gráfico 2, apresentam-se as ocorrências das segmentações não-convencionais encontradas na Escrita autônoma inicial e na Escrita autônoma final. Vale salientar que a escolha desses participantes se deu pelo maior nível de ocorrências encontradas em seus textos. 
GRÁFICO 2: Distribuição de ocorrências de hipersgmentação e hipossegmantação específico de cada participante

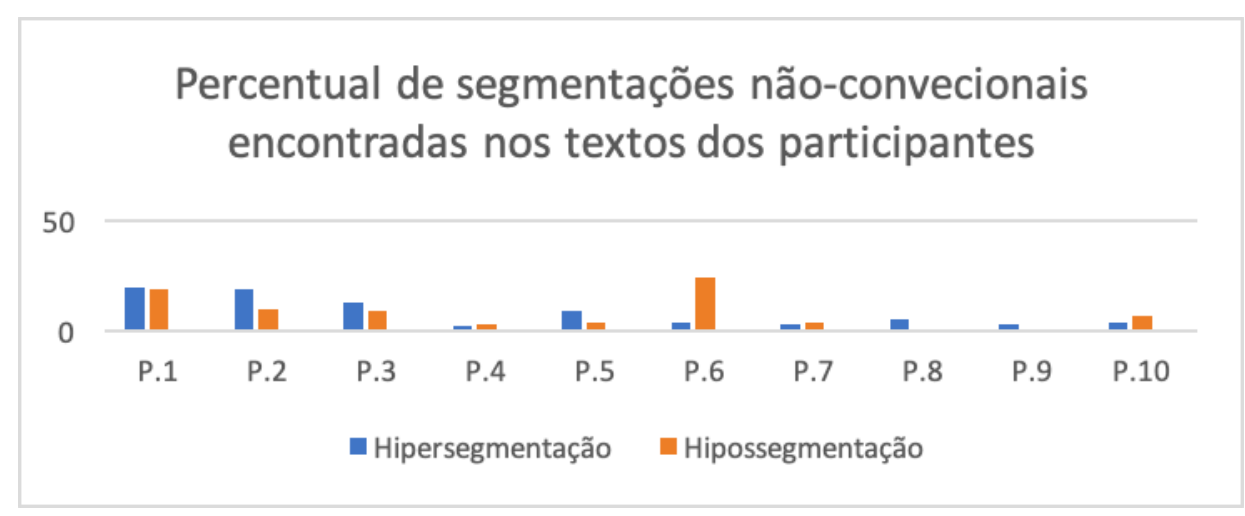

Fonte: Produzido pelas pesquisadoras

Nas tabelas 1 e 2, são apresentadas as ocorrências das estruturas hipossegmentadas e hipersegmentadas encontradas na primeira e segunda produção, respectivamente.

TABELA 1: Ocorrências- segmentações não-convencionais na primeira produção escrita

\begin{tabular}{lccccccccccc}
\hline $\begin{array}{c}\text { Segmentações } \\
\text { não- } \\
\text { convencionais }\end{array}$ & $\mathbf{P . 1}$ & $\mathbf{P . 2}$ & $\mathbf{P . 3}$ & $\mathbf{P . 4}$ & $\mathbf{P . 5}$ & $\mathbf{P . 6}$ & $\mathbf{P . 7}$ & $\mathbf{P . 8}$ & $\mathbf{P . 9}$ & $\mathbf{P . 1 0}$ & Total \\
\hline Hipersegmentação & 15 & 13 & 7 & 2 & 5 & 2 & $\ldots$. & 1 & 1 & 1 & 47 \\
Hipossegmentação & 6 & 5 & 3 & 1 & 2 & 9 & 1 & $\ldots$. & 2 & 1 & 30 \\
Total & 21 & 18 & 8 & 3 & 7 & 11 & 1 & 1 & 2 & 3 & 74 \\
\hline
\end{tabular}

Fonte: Produzido pelas pesquisadoras

Como mostra a tabela 1, houve um predomínio das ocorrências das estruturas hipersegmentadas $(63,5 \%)$ em relação às hipossegmentadas (40,5\%). Esses dados, vão de encontro a outras pesquisas já realizadas, a exemplo a de Brandão (2015) em que as estruturas hipossegmentadas foram mais recorrentes. Essa diferença pode ser explicada devido a um quantitativo mais elevado de estruturas hipersegmentadas detectadas em produções específicas dos participantes 1 e 2 . Essa constatação reflete as dificuldades destes estudantes na modalidade escrita da língua e, ao mesmo tempo, evidencia a sua necessidade de aprimoramento de sua competência escrita no processo de consolidação da alfabetização.

Conforme apresenta a tabela 2 , houve uma diminuição significativa dos dados de hipossegmentação e hipersegmentação quando comparado à primeira escrita Numericamente, verifica-se uma redução de 47 para 11 dos casos de hipersegmentação e 30 para 9 nos casos de hipossegemntação. E a despeito da diminuição dessas estruturas hipersegmentadas, da primeira para a segunda produção, observa-se que os participantes ainda continuam segmentando indevidamente determinadas palavras. Entretanto, as segmentações que ocorreram na segunda produção foram, em sua maioria, ocorrências de novas estruturas. 
Volume 14 - Número 1 - mai/ago de 2019

TABELA 2: Dados quantitativos das segmentações não-convencionais na primeira produção escrita

\begin{tabular}{lcccccccccccc}
\hline $\begin{array}{c}\text { Segmentações } \\
\begin{array}{c}\text { não- } \\
\text { convencionais }\end{array}\end{array}$ & $\mathbf{P . 1}$ & $\mathbf{P . 2}$ & $\mathbf{P . 3}$ & $\mathbf{P . 4}$ & $\mathbf{P . 5}$ & $\mathbf{P . 6}$ & $\mathbf{P . 7}$ & $\mathbf{P . 8}$ & $\mathbf{P . 9}$ & $\mathbf{P . 1 0}$ & Total \\
\hline Hipersegmentação & 2 & 3 & 1 & $\ldots$ & 1 & $\ldots$ & 1 & 1 & 1 & 1 & 11 \\
$\begin{array}{l}\text { Hipossegmentação } \\
\text { Total }\end{array}$ & 3 & 1 & $\ldots$ & 1 & 1 & 1 & 1 & $\ldots$ & 1 & $\ldots$ & 9 \\
ocorrências de & 5 & 4 & 1 & 1 & 2 & 1 & 2 & 1 & 2 & 1 & 20 \\
\hline
\end{tabular}

Fonte: Produzido pelas pesquisadoras

Considerando que os fenômenos de hipossegmentação, como referido antes, são estruturas compostas por duas ou mais palavras grafadas sem a alocação de um espaço em branco ou do hífen para separá-las, segundo a convenção ortográfica da língua, explicitamos, na tabela 3, a quantidade de hipossegmentação distribuída nas quatro modalidades que envolvem a variável tipo de palavra. Dessa forma, são demonstrados os números absolutos e a respectiva percentagem no que se refere ao total de ocorrências nas produções dos participantes na Escrita Autônoma (inicial).

TABELA 3: Ocorrências de hipossegmentação encontradas na Escrita Autônoma (inicial)

\begin{tabular}{lcc}
\hline \multicolumn{1}{c}{ Tipo de palavra } & Quantidade & Percentual \\
\hline Palavra gramatical + palavra fonológica & 22 & $73,3 \%$ \\
Palavra fonológica + palavra gramatical & 3 & $10 \%$ \\
Palavra gramatical + palavra gramatical & 2 & $6,7 \%$ \\
Palavra fonológica + palavra fonológica & 3 & $10 \%$ \\
Total geral & 30 & $100 \%$ \\
\hline
\end{tabular}

Fonte: Produzido pelas pesquisadoras

Conforme mostram os dados na tabela 3, o maior número de hipossegmentação ocorreu na modalidade palavra gramatical + palavra fonológica, ou seja, $22(73,3 \%)$ casos das estruturas hipossegmentadas. Os dados também apresentam que a maioria das estruturas hipossegmentadas envolve uma palavra gramatical, ou seja, a palavra fonológica agrega-se ou é agregada a uma palavra gramatical.

Esses resultados evidenciam que as palavras gramaticais ou clíticos são palavras problemáticas para o aprendiz do código escrito, conforme salienta Bisol (2000). Para Cunha (2004, p. 106), o produtor na fase inicial de aquisição da língua escrita encontra "dificuldade em considerar segmentos de uma ou duas letras como palavra, por isso, na maioria das vezes, junta esses segmentos à palavra seguinte".

As estruturas hipossegmentadas que envolvem elementos clíticos como as preposições e conjunções e seu hospedeiro, ou seja, a palavra gramatical mais a palavra fonológica, respectivamente (para come eela foi maela tava - P.1 / denoite eli fez uma - P.2). Assim, notamos ainda que as preposições de, pra (para) e as conjunções mas e e, estão sempre se unindo a uma palavra fonológica, pois segundo Bisol (2005), isso decorre da falta de acento fonológico dessas palavras, uma vez que, por não possuir independência fonológica, o produtor não a reconhece como palavra, e por este motivo faz a juntura com a palavra fonológica, como ocorreu nas palavras: eela grafada para e ela; denoite grafada para de noite; demilho grafada para de milho; decasa grafada para de casa e decastigo grafada para de castigo; maela grafada para mas ela, nessa estrutura é possível verificar um processo fonológico apócope que é um tipo de elisão, pois na juntura da conjunção mas e o pronome ela ocorreu o apagamento do fonema [J], no final do vocábulo.

$\mathrm{E}$ os artigos $a$, as e $o$ se juntam às palavras fonológicas, que, nesse caso, são os pronomes e substantivos. Isso decorre da falta de acento dessas palavras gramaticais, como mostram os exemplos: omeu e roberto ele olhou para - P.6 / araposa e asuvas - P.1 / amossa 
muito abalada - P.6 /ele perguntol oseu nome p.6. Esse fato mostra o não reconhecimento dessas letras como sendo uma palavra, levam a essas junções. Segundo Cunha (2004), os produtores em fase inicial da aprendizagem da escrita têm essa dificuldade, entretanto, observa-se que esta dificuldade se estendeu para esses participantes do Ensino Fundamental II.

As estruturas que são oriundas da junção de uma palavra fonológica e de uma palavra gramatical tiveram poucas ocorrências, ou seja, apenas $10 \%$ das estruturas hipossegmentadas. Como é verificado nos exemplos a seguir, essas segmentações indevidas só foram encontradas na escrita autônoma inicial de um único participante (P.1): derubalas as uvas (derrubá-las) P. 1 / um problema tinhaum bandu- (tinha um) - P.1 leraun aves uma araposa fa mím ta -P. 1.

Percebemos, ainda, que a ocorrência derubalas é uma estrutura hipossegmentada caracterizada pela ausência do hífen entre o verbo (palavra fonológica) e um grupo clítico (palavra gramatical) que é representado por um pronome átono. Assim, essa junção resultou em uma polissílaba paroxítona de pé troqueu. Já as estruturas tinhaum e eraun são palavras formadas pelas junções de dois verbos tinha e era, respectivamente, e dois artigos um e un grafado para um. Essas hipossegmentações resultaram em duas palavras trissílabas oxítonas de pé iambo.

Já as estruturas hipossegmentadas, que resultam da alocação de duas palavras gramaticais, ocorreram apenas duas vezes, sendo a estrutura 'eo', grafada para $e o$, e ' $e a$ ' grafada para $e a$, resultantes da junção de dois clíticos, isto é, palavras gramaticais, que são a conjunção "e" e os artigos "a" e "o". Estruturas desse tipo só foram encontradas na produção de apenas dois participantes (Bela eo Vampiro - P.4 / O lobo ea mossa - P.5). Logo, estruturas desse tipo, também foram encontradas nos estudos realizados por Cunha (2004) e Brandão (2015). Entretanto, nestas duas pesquisas, essas estruturas só foram encontradas no início de frases, mas na pesquisa presente, observam-se essas segmentações no meio da frase e ambas realizadas no título das narrativas.

As ocorrências da alocação de duas palavras fonológicas foram encontradas nas produções dos participantes em apenas três vezes, sendo uma do P.5 e duas do P.6, conforme mostram os exemplos tábom ( eu vol - P.5 / é letísia elindo - P.6 / jaestava ficando di noiteP.6)

Essas ocorrências referem-se às sequências de duas palavras fonológicas que, por não haver um contorno prosódico, formam frases fonológicas. De acordo com Tenani (2011), a construção da constituinte frase fonológica se dá pela ausência de contorno entonacional entre os elementos que o forma.

Constatamos ainda que, nessas sequências segmentadas de forma não-convencional, surgiram estruturas dissílabas oxítona como em "tábom”; trissílabas paroxítonas em "elindo" e polissílaba paroxítona como em "jaestava”. Quanto ao pé métrico, verifica-se que todas as estruturas são pé troqueu. Em relação à estrutura tábom verifica-se um processo de aférese que é um tipo de elisão, pois houve o apagamento do fonema [e $]$ no início do vocábulo. Fato que mostra uma estrutura considerada hipersegmentada quando é inserido um espaço em branco ou um hífen em seu interior e que deveria ser escrita junta.

Assim como as estruturas hipossegmentadas, as hipersegmentadas foram analisadas a partir da categorização tipo de palavra proposta por Cunha (2004), ou seja, gramatical e fonológica. Dessa forma, as combinações são as mesmas das estruturas hipossegmentadas: a) palavra gramatical + palavra fonológica; b) palavra fonológica + palavra gramatical; c) palavra gramatical + palavra gramatical e d) palavra fonológica + palavra fonológica.

$\mathrm{Na}$ tabela 4, são apresentadas as quantidades de ocorrências de palavras hipersegmentadas oriundas dessas subcategorias. 
Volume 14 - Número 1 - mai/ago de 2019

TABELA 4: Ocorrências de hipersegmentação encontradas na escrita Autônoma (inicial)

\begin{tabular}{lcc}
\hline \multicolumn{1}{c}{ Tipo de palavra } & Quantidade & Percentual \\
\hline Palavra gramatical + palavra fonológica & 33 & $70,1 \%$ \\
Palavra fonológica + palavra gramatical & 5 & 10,1 \\
Palavra gramatical + palavra gramatical & 3 & $6 \%$ \\
Palavra fonológica + palavra fonológica & 8 & $17 \%$ \\
\multicolumn{1}{c}{ Total geral } & 47 & $100 \%$ \\
\hline
\end{tabular}

Fonte: Produzido pelas pesquisadoras

Assim como nas pesquisas realizadas por Cunha (2004) e Brandão (2015), o maior número de estruturas hipersegmentadas encontradas nessa pesquisa também foram classificadas dentro da categoria palavra gramatical + palavra fonológica. Desse modo, observa-se que 39 ocorrências de estruturas hipersegmentadas dizem respeito ao envolvimento da uma palavra gramatical mais a palavra gramatical.

Os casos de hipersegmentação encontrados na Escrita Autônoma (inicial) mostram variável tipo de palavra, que são as combinações proposta por Cunha (2014), a) palavra gramatical + palavra fonológica; b) palavra fonológica + palavra gramatical; c) palavra gramatical + palavra gramatical; d) palavra fonológica + palavra fonológica. Nas estruturas hipersegmentadas, os participantes fragmentaram as palavras, isolando à esquerda uma palavra gramatical, que correspondem a um artigo, uma preposição ou uma conjunção, já a sua direita, uma palavra fonológica que pode ter ou não significado na língua portuguesa. Ao realizar esse movimento, o produtor reconhece uma sílaba da palavra fonológica como se fosse uma palavra gramatical.

Nas ocorrências - éli tinha falado com os caba para a rumar- P.2 / Bela ela era muito a traente! -P.4 Eles não podião se $a$ paichonar - P.4 /ela a gradece a ele -P.4/ Os melhores $a$ migos- P.5 / não a credito nisso vei-P.5, notamos que as segmentações isolam, à esquerda, a sílaba "a". Essa sílaba pode corresponder a palavras gramaticais artigo ou preposição, que são bastante utilizadas na modalidade da língua oral ou na modalidade da língua escrita. Já à esquerda dessa palavra apresentam-se estruturas fonológicas que não são comuns quando comparadas às demais encontradas nas produções dos participantes.

Dessas estruturas hipersegmentadas, apenas uma, das que são isoladas à direita, possui significado na língua portuguesa, que é "credito", esta é uma trissílaba paroxítona. Já as outras palavras fonológicas que não possuem significado na língua portuguesa, duas são dissílabas, sendo uma oxítona rumar e outra paroxítona migos; três trissílabas, sendo duas paroxítonas: traente e gradece e uma oxítona: paichonar. Vale salientar que o deslocamento de "a" não interfere na estrutura rítmica das palavras que são alocadas à direita.

Conforme Tenani (2011), essas estruturas sugerem que o produtor movimenta tanto informações prosódicas - que chegam a transformar uma palavra fonológica em um grupo clítico, como também informações letradas - que o permite separar uma palavra gramatical do restante da palavra (Exemplos: ele vai em bora-P.1 /e ela se em com trou com um galo - P.1)

Esses exemplos apresentam duas estruturas que envolvem a palavra gramatical “em". Conforme as pesquisaoras Cunha (2004) e Tenani (2011), segmentações desse tipo podem ter sido motivadas pelo reconhecimento da palavra gramatical "em" escrita à esquerda. Nessa mesma linha de pensamento, Capristano (2007, p.9), ao se referir sobre os casos de hipersegmentação, aponta a presença de padrões da escrita ao afirmar que "os pontos de corte, nesses dados, parecem ser momentos em que a criança reconheceu unidades que na escrita aparecem com frequência separadas: em bora, na quela ou em com tado.

A segmentação não-convencional da palavra embora resultou, à direita, em uma palavra dissílaba paroxítona de pé troqueu, conforme 9a. Já a estrutura em com trou resulta na formação de dois clíticos 'em' e 'com' mais uma palavra fonológica sem significação na língua portuguesa. 
Os exemplos, e com vidou para no canto das- P.1 / é os corvos com mesol air- P.2, apresentam estruturas hipersegmentadas que envolvem a palavra gramatical "com". Para Cunha (2004), uma das motivações para essa segmentação é o reconhecimento de uma palavra gramatical. Ainda de acordo com esta pesquisadora, a criança faz o isolamento da sílaba “co" e em seguida acrescenta a coda nasal 'm' para formar a preposição 'com'.

Ocorrências semelhantes às estruturas analisadas por Cunha $(2004$, p.108), foram observadas nos trechos - a araposa quan do -P.1 / que quarava pelo mum do efutava- P.1 / e a raposa derrubou mas ela prede $u-P .1$ / a peso $u a$ atei que galha e pede.- P. 3 / rico i sua ideia de $u$ muiceto -P.3-), pois essa pesquisadora, ao analisar ocorrências como: gitan do grafada para gritando e correm do grafada para correndo, diz que é provável que essas segmentações tenham sido motivadas devido à presença da nasal e à tonicidade da palavra, visto que elas foram fragmentadas "logo após uma sílaba tônica com coda" nasal"(CUNHA, 2004, p.108). Dada esta explicação, pode-se lançar mão para explicar a hipersegmentação ocorrida na palavra 'mum do', e 'quan do', uma vez que elas foram fragmentadas após uma sílaba tônica com coda nasal. Já as estruturas 'prende u', 'de u', isoladas à direita, não são correspondentes a palavras gramaticais, entretanto, a estrutura ' $u$ ' pode ser considerada como uma variante de uma palavra gramatical 'o', dessa forma, optou-se para ser analisada nesse tipo de palavra.

No que diz respeito às ocorrências de hipersegmentação envolvendo duas palavras gramaticais, só foram encontradas duas estruturas com esse tipo de palavra, como mostram os exemplos (ficol muito rico i sua ideia de $u$ muiceto-P.3 / Em 1880 nua linda prasa um a linda mosa- P. 6).

As duas estruturas hipersegmentadas, apresentadas acima, são compostas por elementos muito conhecidos na língua portuguesa, ou seja, a preposição de, no primeiro excerto e os artigos um e a no segundo, isto é, palavras gramaticais. Deste modo, pode-se afirmar que essa hipersegmentação é decorrente do conhecimento desses participantes em relação a essas palavras gramaticais. E as estruturas hipersegmentadas que geraram tanto à esquerda como à direita sequências correspondentes a palavras fonológicas (Exemplos: eli fez uma fes tar com muita pamanha -P.2 / Va esperar e des ligo ai ele boto escorado- P-5 / Ois dois jantaro e foro dor mir-P.5)

A criação de três modalidades diferentes de estruturas hipersegmetadas envolvendo as palavras fonológicas também foi percebido no corpus. A primeira diz respeito à modalidade que segmenta indevidamente a palavra fonológica e dá origem a duas palavras lexicais, são elas: 'come sol' grafada para começou; 'vem der' grafada para vender. Todas essas sequências de palavras possuem significado na língua portuguesa. A segunda modalidade refere-se à palavra fonológica que se desmembrou em duas, sendo uma lexical e outra sem significado na língua, assim, temos: 'dor mir' grafada para dormir; 'des ligo' grafada para desligou e 'licom vido' grafada para lhe convidou. Já a terceira modalidade é a transformação de uma palavra fonológica em duas palavras sem significação na língua. Como é o caso das palavras:'fes tar', grafada para festa.

Na tabela 5, apresentamos quatros modalidades que envolvem a variável tipo de palavras. Assim, mostramos os números absolutos e a respectiva porcentagem das ocorrências detectadas nas produções dos participantes na Escrita autônoma (final).

TABELA 5 Ocorrências de hipossegmentação identificadas na escrita autônoma (final)

\begin{tabular}{lcc}
\hline \multicolumn{1}{c}{ Tipo de palavra } & Quantidade & Percentual \\
\hline Palavra gramatical + palavra fonológica & 7 & $88 \%$ \\
Palavra fonológica + palavra gramatical & $\ldots$ & $\ldots$. \\
Palavra gramatical + palavra gramatical & 1 & $12 \%$ \\
Palavra fonológica + palavra fonológica & 1 & $12 \%$ \\
Total geral & 9 & $100 \%$ \\
\hline
\end{tabular}

Fonte: Produzido pelas pesquisadoras 
As junções que envolvem palavra gramatical + palavra fonológica, foram, novamente, as mais recorrentes, ou seja, detectaram-se sete ocorrências desse tipo de palavra na escrita autônoma final. No entanto, em uma quantidade menor em relação às identificadas na escrita autônoma (inicial). Nessas ocorrências, observa-se que a hipossegmentação acontece sempre envolvendo um clítico (artigo e preposição). Deste modo, verifica-se que o elemento clítico se hospeda na palavra portadora de acento que é a palavra fonológica.

Em relação à análise métrica, temos: na estrutura 'ifes' uma palavra dissílaba oxítona de pé iambo; três trissílabas paroxítonas de pé troqueu, conforme mostram os exemplos (na.frente.te/ po.cau.sa/ um.de.les). Também, há uma palavra polissílaba paroxítona em 'sechamava' de pé troqueu. Já a estrutura 'pocausa' grafada para por causa, temos um processo de elisão, uma vez que a segmentação indevida resultou no apagamento de um fonema.

$\mathrm{Na}$ escrita autônoma final, só foram identificadas duas estruturas envolvendo duas palavras gramaticais, esse fato também ocorreu na escrita autônoma inicial. Uma das estruturas hipossegmentadas na escrita autônoma (final), é reincidente, uma vez que essa ocorrência fora detectada na escrita autônoma inicial, resultantes da junção de dois clíticos, ou seja, duas palavras gramaticais, que são a conjunção "e" e o artigo "o" (os homes estavam no jardim das crianças eo jardim estava com pegadas- P.3 / eles começaram a joga eo dono do campo jogou com eles. - P.6).

Na produção final, só foi identificada apenas uma ocorrência de estrutura envolvendo duas palavras fonológicas. Essa estrutura é a sequência de duas palavras fonológicas, que por não ter contorno prosódico formam uma frase fonológica. Em relação à variável tipo de palavra e variável tipo de constituinte prosódico das estruturas hipersegmentadas identificadas na escrita autônoma (final), notamos que ocorreu, na escrita autônoma inicial, o maior número de ocorrências das estruturas hipersegmentadas ocorreu na modalidade palavra gramatical mais a palavra fonológica. Desse modo, verifica-se que $75 \%$ são palavras envolvem uma palavra gramatical e uma palavra fonológica, conforme mostra a tabela 6 .

TABELA 6: Ocorrências de hipersegmentação identificadas na escrita autônoma (final)

\begin{tabular}{lcc}
\hline \multicolumn{1}{c}{ Tipo de palavra } & Quantidade & Percentual \\
\hline Palavra gramatical + palavra fonológica & 12 & $75 \%$ \\
Palavra fonológica + palavra gramatical & 1 & $6 \%$ \\
Palavra gramatical + palavra gramatical & $\ldots$. & $\ldots$. \\
Palavra fonológica + palavra fonológica & 3 & $19 \%$ \\
Total geral & 16 & $100 \%$ \\
\hline
\end{tabular}

Fonte: Produzido pelas pesquisadoras

Em estudos realizados por Tenani (2011), os dados de hipersegmentação apresentaram uma característica prosódica predominante, assim, foi representado por esta pesquisadora da seguinte forma: $\omega>\mathrm{cl}+\omega$. Nessa representação, Tenani indica que uma palavra fonológica, quando fragmentada, gera uma estrutura formada por uma palavra gramatical e uma fonológica.

$\mathrm{Na}$ escrita autônoma final, foram encontradas estruturas hipersegmentadas que envolveram uma palavra gramatical mais uma palavra fonológica. Assim, pode-se considerar que essas estruturas hipersegmentadas foram motivadas pelo reconhecimento dessas palavras gramaticais por parte do escrevente, como nos exemplos - 'em tão', 'da quele', 'com tinuaram' e 'a migos'.

$\mathrm{Na}$ última produção, só fora encontrada apenas uma ocorrência desta combinação de palavra. A hipersegmentação desta estrutura resultou em uma palavra lexical a esquerda 'par' e uma palavra gramatical à direita 'que'. Certamente, o conteúdo dessas palavras é de conhecimento do participante e isso pode ter desencadeado essa hipersegmentação. (Exemplo: ele vio que seu par que ficou - P.4). 
Em relação à combinação de duas palavras fonológicas, foram identificadas três ocorrências nessa segunda produção, o mesmo fato ocorreu na primeira. Essa hipersegmentação resultou em palavras lexicais, isto é, palavras com significado na língua portuguesa, apesar do segmento 'tou' não ser uma palavra dicionarizada, ela é uma variante do verbo 'estou' que é muito utilizada por estes participantes, conforme os exemplos ( ai o dele gado sol tou de novo - P. 2 / No certo dia em um castelo a via um príncipe que si chamava Alef. - P.7).

Desse modo, entendemos que estes estudantes foram expostos a um ensino frágil da ortografia, ou seja, um trabalho que não levou em conta a capacidade que o aluno tem em refletir sobre o seu objeto de aprendizagem e de criar suas hipóteses na construção do conhecimento. Entretanto, para que isso ocorra é preciso que o professor de Língua Portuguesa tenha embasamento teórico-metodológico para enfrentar as dificuldades do aluno, através de uma intervenção.

\section{Considerações Finais}

A utilização do projeto didático foi fundamental para a realização deste trabalho, uma vez que este consiste em um programa de letramento regido por um sistema coerente e objetivo, visando, principalmente, à leitura e à escrita de texto, sendo estes os principais focos do ensino de Língua Portuguesa. No decorrer da aplicação, foi possível perceber que os estudantes tinham inúmeras dificuldades e, a despeito de estarem no $7^{\circ}$ ano do Ensino Fundamental, não compreendiam as questões mais básicas da língua, ou seja, a relação existente entre os fonemas e sua representação grafêmica, pois essa é uma problemática que deveria ter sido sanada nos anos iniciais.

As análises aqui realizadas demonstraram a necessidade de um olhar mais reflexivo sobre os recorrentes problemas relacionados à grafia das palavras, pois a tarefa de segmentar a cadeia da fala para representá-la graficamente é um ainda complexa para esses alunos dos Anos Finais do Ensino Fundamental. Assim, considera-se ser pertinente a realização de atividades que os levem à reflexão da escrita de determinadas palavras, assim como à compreensão de variadas palavras, em seus diferentes contextos, para só assim utilizá-las conscientemente.

Nos casos das segmentações não-convencionais, verificamos que há um predomínio do envolvimento de elementos clíticos, tanto nos casos de hipossegmentação como também nos de hipersegmentação. Assim, foi possível perceber que a grande dificuldade dos participantes está no uso das palavras gramaticais. Em relação à estrutura métrica contidas nas palavras fonológicas, identificou-se um número significativo de elementos dissílabos e trissílabos de estrutura trocaica. Esse fato mostra a preferência dos falantes do PB pelo ritmo trocaico, como também demonstra que os participantes, ao tentarem representarem as palavras, fizeram a busca pelo que é mais regular em sua língua.

Em relação ao total de dados coletados, observou-se que há uma relação muito equilibrada entre as ocorrências de hipersegmentação (51\%) e hipossegmentação (49\%). Esses dados podem revelar um processo de letramento escolarizado dos participantes. Houve, também, em várias produções, o que Tenani (2010) chama de flutuação, pois ora o estudante escrevia fugindo às normas ortográficas, ora escrevia conforme a convenção da língua. Esse fato revela que o produtor está refletindo sobre a modalidade escrita da língua. Por estes motivos, não se pode dizer que tais ocorrências são, simplesmente, decorrentes apenas da falta de conhecimento desses estudantes sobre as normas ortográficas, mas também que estão refletindo e, a partir disso, construindo e apropriando-se da língua escrita. No entanto, para que isso ocorra, necessita-se da realização de atividades que os levem a essa reflexão, como as que aqui foram realizadas. 
No que diz respeito às ocorrências das estruturas hipossegmentadas, identificadas na escrita autônoma inicial e final, houve um predomínio da variável tipo de palavra - palavra gramatical + palavra fonológica, nas duas produções. Entretanto, com valores bastante reduzidos entre as duas produções. Assim, na primeira foram identificadas 22 estruturas resultantes da junção de palavras gramaticais mais a palavra fonológica e, na segunda, 7 dessas ocorrências.

Assim, como os casos de hipossegmentação, verificamos também, a predominância do tipo de palavra - palavra gramatical + palavra fonológica nas estruturas hipersegmentadas, isto é, a separação de uma palavra em duas, que resultou em uma palavra gramatical e outra fonológica, como em "a rumar" e "a traente" e a separação de uma palavra em duas fonológicas como em "come sol e "dor mir". Os dados que envolvem uma palavra gramatical mais uma palavra fonológica demonstram o reconhecimento do estudante de palavras gramaticais na sílaba inicial como sendo uma palavra e, ao isolar, formam duas palavras. Assim, as palavras formadas em sua maioria são dissílabas e trissílabas de pé troqueu. No que se refere à influência da prosódia, observou-se que os constituintes mais relevantes são a sílaba e a sílaba portadora de acento, formando, assim, o pé métrico.

Dessa forma, podemos dizer que, como salienta Cunha (2004), a decisão da criança ao segmentar um texto é resultante de vários processos, envolvendo, geralmente, mais de uma motivação. Desse modo, esse trabalho revelou-se importante por mostrar que o professor de Língua Portuguesa precisa fazer com que a sala de aula seja um lugar privilegiado para o desenvolvimento satisfatório do texto escrito, mediante a liberdade de testar suas hipóteses. Por fim, este estudo traz contribuição para os estudos linguísticos, fortalecendo o diálogo entre a Pedagogia de Gêneros e aos aspectos fonológicos da Língua Portuguesa.

\section{Referências}

ABAURRE, M.B.M. Horizontes e limites de um programa de investigação sobre a aquisição da escrita. In: LAMPRECHT, R. R. (Org.) Aquisição da linguagem: Questões e análises. Porto Alegre: Edipucrs, 1999. p.167-186.

BRANDÃO, M. H. Uma abordagem fonológica da segmentação na escrita de alunos do ensino fundamental II. 200 f. 2015. Dissertação de Mestrado em Linguagens e Letramentos. Uberlândia, UFU, 2005.

BORTONI-RICARDO, S. M. O professor pesquisador: introdução à pesquisa qualitativa. São Paulo: Parábola Editorial, 2008.

BISOL, L. Introdução a estudos de fonologia do português Brasileiro. Porto Alegre,1999. A sílaba e seus constituintes. In: NEVES, M. H. M. (Org.) Gramática do Português Falado. v. 7: Novos Estudos. Campinas: Ed. da UNICAMP, 1999. p. 701-742.

O clítico e seu status prosódico. Revista de estudos de linguagem. Belo Horizonte.

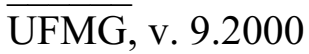

BISOL, Leda. Mattoso Câmara Jr. A Palavra Prosódica. D.E.L.T.A., 20; Especial, 2004, p.61.

. O clítico e seu status prosódico. Revista de Estudos da Linguagem, v.9, n.1, jan./jun. 2000. p. 4-30. BISOL, L. O clítico e seu hospedeiro. Letras de Hoje, v.40, n.3, set.2005. p.163-184.

O acento: Duas alternativas de análise. Porto Alegre, v.28, n.54, p.281-321,2013. CAGLIARI, L. C.; MASSINI-CAGLIARI, G. Diante das letras: a escrita na alfabetização. Campinas: Mercado das Letras, 1999. . Alfabetização \& Lingüística. São Paulo: Editora Scipione, 2002.

CAPRISTANO, C. C. Segmentação na escrita infantil. São Paulo: Martins Fontes, 2007. CHACON, L. Constituintes prosódicos e letramento em segmentações não convencionais. Letras de Hoje. Porto Alegre. v. 39. n. 3, p.223-232, 2002. 
Hipersegmentações na escrita infantil: entrelaçamentos de práticas de oralidade e letramento. Estudos linguísticos. Campinas, 2005, v. 34, p. 77-86.

CUNHA, A.P.N. A hipo e a hipersegmentação nos dados de aquisição da língua escrita: um estudo sobre a influência da prosódia. 132f- Curso de Mestrado em Educação, Faculdade de Educação, Universidade Federal de Pelotas, Pelotas, 2004.

. ; MIRANDA, A. R. M. A hipo e a hipersegentação nos dados de aquisição de escrita: A influência da prosódia.127Alfa, São Paulo, 53 (1): 127-148, 2007.

MARTIN, J. R.; ROSE, D. Genre relations: mapping culture. Londres: Equinox, 2008.

MOREIRA, N. da C. R. O nome próprio na aquisição da escrita: construção da nasal préconsonantal. Tese de Doutorado em Letras. Pontifícia Universidade Católica de São Paulo, 1991.

ROSE, D; MARTIN, J. R. Learning to Write, Reading to Learn: Genre, Knowledge and Pedagogy in the Sydney School. Londres: Equinox, 2012.

Rothery, J.; Stenglin, M. Exploring Literacy in School English (Write it Right Resources For Literacy and Learning),1994.

ROTHERY, J. Making changes: developing an educational linguistics, 1996 In: BUNZEN, C. O ensino de "gêneros" em três tradições: implicações para o ensino-aprendizagem de língua materna. Universidade Federal de São Carlos (SP), 2003.

TENANI, L. A grafia dos erros de segmentação não-convencional de palavras. Cadernos de Educação, Pelotas, v. 35, pp. 247-269, 2010.

A segmentaçãonão convencional de palavras em textos do ciclo II do Ensino

Fundamental. Revista da ABRALIN, v.10, n.2, jul./dez.2011.

Fonologia prosódica. In: DERMEVAL, H.; MATZENAUER, C. (Org.) Fonologia, fonologias. São Paulo: Contexto, 2017, pp. 109-123. 